\title{
Value of ultrasound in grading the severity of sarcopenia in patients with hepatic cirrhosis
}

\author{
Nevien Ezzat El-Liethy* ${ }^{*}$ and Heba Ahmed Kamal 1
}

\begin{abstract}
Background: Ultrasound is emerging as an efficient significant method for measuring muscle mass in patients with liver cirrhosis. It has been applied in numerous studies as an accurate measuring tool for the muscles of the limbs. This study was conducted to assess the severity of sarcopenia in liver cirrhosis patients, through utilizing ultrasound in measuring the cross-sectional area and consequently estimating the muscle mass of both the upper and lower limb muscles, than correlating the results with hand grip strength as representative of functional status. Also, the severity of sarcopenia was correlated with conventional prognostic scores for liver cirrhosis, like Child or MELD scores and detecting its effect on the duration of hospital stay and mortality.

Results: This study was conducted on 101 liver cirrhosis patients who were admitted to the internal medicine hospital, 30 healthy participants were added as a control group. Using the FNIH (Foundation for the national Institutes of health) cuff off of hand grip ( $<26 \mathrm{~kg}$ in male and $<16 \mathrm{~kg}$ in female, Quadriceps muscle index cutoff was estimated to be $\left(1.67 \mathrm{~cm} / \mathrm{m}^{2}\right.$ for male and $1.58 \mathrm{~cm} / \mathrm{m}^{2}$ for female).

Ultrasound (mid upper arm, mid-thigh and Quadriceps muscle index) showed significant indirect correlation with (Child even in Child A and MELD) scores, as well as with the duration of hospital stay. Also, they showed a direct correlation with HGS.

Conclusion: Sarcopenia in cirrhotic patients assessed by ultrasonography of (mid upper arm, mid-thigh muscle thickness) and HGS are independent predictors of disease severity and poor outcome, which is assessed by high Child and MELD scores. Also, ultrasound and HGS are straightforward bedside techniques used for assessment of sarcopenia.
\end{abstract}

\section{Background}

Skeletal muscle is the amplest tissue within the anatomy in adults, in keeping with the Davis law (the corollary to the Wolff law for bone), muscles are generally remarkably plastic, with the flexibility to achieve or lose tissue playing on several factors. Muscle depletion commonly occurs with aging, chronic disease, and disuse, but may go unrecognized by clinicians [1].

Sarcopenia, first proposed by Irwin Rosenberg in 1989, is characterized by a progressive loss of muscle

*Correspondence: nevienelliethy@yahoo.com

Department of Diagnostic and Interventional Radiology, Faculty

of Medicine, Kasr Al-Aini, Giza, Egypt mass and is related to chronic disease. It reduces muscle strength and performance [1].

Sarcopenia-broadly defined as a significant loss of muscle mass and function-is increasingly identified as a crucial independent risk factor for varied adverse outcomes. These negative outcomes include physical disability, osteoporosis, fractures, prolonged hospital stay and re-admission. Subsequent, operational definitions also incorporate functional criteria (e.g., low muscle strength measured by hand grip strength) $[2,3]$.

In cirrhotic patients, it was reported that loss of rectus femoris muscle cross-sectional area (CSA) was encountered due to increased protein turnover and an imbalance between muscle protein synthesis and protein degradation. From a conceptual point of view, muscle 
mass assessment in these patients may help detect at-risk patients and predict the patient outcome. Furthermore, monitoring muscle mass may allow physicians to successfully identify patients who would benefit the foremost from tailored nutritional interventions $[4,5]$.

The diagnostic criteria for sarcopenia don't seem to be yet uniform. The diagnostic index for sarcopenia includes muscle mass, muscle strength (usually reflected by hand grip strength) and physical performance (usually reflected by gait speed) $[2,6]$.

Because muscle mass is considered to be one of the most important parameters for grading sarcopenia, its measurement techniques have received widespread concerns. The mostly used are Dual-energy X-ray absorptiometry (DXA) and bio-electrical impedance analysis (BIA). Computed tomography (CT) and magnetic resonance imaging (MRI) are nominated as the gold standard for assessing muscle mass because they clearly show the tissue structure. However, Ultrasound, being convenient and pocket-friendly, is usually recommended. Although the literature and guidelines suggest that the gold standard for muscle mass testing is CT or MRI, these two methods have some limitations, they're time-consuming expensive, and need specialized equipment, also CT has ionizing radiation hazards, because of these limitations, the employment of CT and MRI as a measuring tool for the muscle mass within the elderly has not yet peaked $[7,8]$.

When the target sarcopenic population is expected to be frail, elderly, and immobile, the imaging technique must be easily accessible, both geographically and physically, cheap, simple and can be done along the bedside, thus, rendering ultrasound a clearly better option than the previously mentioned modalities, specifically, as it offers a non-invasive, portable, and safe imaging technique, whilst having the extra benefits of maintaining image clarity, being widely utilized in medicine, familiar to clinicians, reliable and simply interpreted by the lay sonographer $[9,10]$.

However, several questions remain. First, should (or can) sarcopenia be diagnosed in single or composite anatomic sites, and second, which site or sites should be used? the selection of site, especially if only one peripheral site is employed, should otherwise be an appropriate surrogate marker of broader muscle mass, particularly appendicular muscle mass (ASM) or total muscle mass (TMM). However, evidence that ultrasound can accurately predict whole-body muscle mass is insufficient and it must be considered that not all peripheral muscles decline alike. As such, prediction equations for TMM (and ASM) from ultrasound-derived sites need further validation [11-13].
Measurement of the (quadriceps) rectus femoris (RF) cross-sectional area (CSA) is widely used as a marker for muscle size in clinical research. The rationale for these measures can be explained by its tolerability by participants, easily accessible position, simple method in acquiring its location accurately, and robust association with functional strength [14].

With ultrasound increasingly used as a good and valid muscle-imaging tool in liver cirrhosis, ultrasound based measurements cut-off points are progressively needed for both sexes, to assess the condition of an individual's muscle, as well as help early and accurate detection of sarcopenia, this might help distinguish those at greater risk and aid in targeted treatment programs [14].

Few studies have focused on the importance of assessing upper limb muscles using ultrasound. For a far better understanding of the biceps muscle thickness (MT), cross-sectional area (CSA) and fat thickness (FT) measured by ultrasound in sarcopenic patients, a comparative analysis was performed between FT, MT, CSA of biceps, muscle mass, grip strength against the severity of sarcopenia [2].

The muscle thickness of the forearm was also significantly correlated to the grip strength [15]. Positive correlations between CSA of the biceps brachii and SMI or grip strength were observed in both genders.

Therefore, there's an urgent need for a customary and uniform measurement of sarcopenia. Ultrasound is universally accustomed diagnose and follow-up within the clinic. It can distinguish muscle tissue from subcutaneous fat and show the thickness and cross-sectional area of muscle. It's a convenient, reliable and non-radiative technique, and might be performed at the bedside for those that cannot cooperate with DXA, CT or MRI. Compared with the above methods, the appliance of ultrasound is more common, and lots of people are more willing to just accept the ultrasound examination, which contains a great prospect within the application for sarcopenia. It's been got wind as a good method to assess muscle mass within the elderly [16].

The Foundation for the National Institutes of Health Sarcopenia Project [5] recommends specific cutoff points to spot populations with functional limitations related to sarcopenia. These evidence-based criteria recognize measures of low muscle strength (i.e., grip strength $<26 \mathrm{~kg}$ for men and $<16 \mathrm{~kg}$ for women) and low lean body mass (i.e., appendicular lean mass adjusted for body mass index [BMI; weight in kilograms divided by the square of height in meters] $<0.789$ for men and $<0.512$ for women) [14]. These criteria were validated as predictive of future mobility impairment with a 3-year clinical follow-up [14], and this definition of muscle 
weakness appears to be a treatable symptom of sarcopenia [15].

The purpose of this study was to validate the utilization of ultrasound measurement as a measure of muscle mass and predictor of sarcopenia in liver cirrhosis patients and its relevance conventional prognostic scores for liver cirrhosis, like (MELD) scores similarly as detecting its effect on morbidity and mortality.

\section{Methods}

The current study was an observational prospective study conducted during the period from November 2018 to December 2020, 101 patients with liver cirrhosis and 30 control participants, to validate and emphasis the role of ultrasound measures in assessing the severity of sarcopenia and help in management of liver cirrhosis.

The ethics commission of our institution approved this study and written consent for this study from all patients before enrollment was obtained.

\section{Patients}

The study included 101 liver cirrhosis patients.

The inclusion criteria included the following:

- Adult patients previously diagnosed to possess liver cirrhosis, either by biopsy or abdominal ultrasound (based on the morphological characteristics of cirrhosis, including hepatic contour, texture, and also the presence of portal collaterals)

- Admitted to the hospital by a complication of liver cirrhosis (hematemesis, spontaneous bacterial peritonitis, hepatic encephalopathy, hepatorenal syndrome).

The exclusion criteria included the following:

- History of organ failure, which interferes with nutritional status e.g. end stage nephrosis on hemodialysis, coronary failure, and respiratory failure).

- Malignancies and hepatocarcinoma

- Acute liver cell failure.

All patients were submitted to the following:

Patients were fully informed about the risks and benefits of the radiological procedures; they were also informed about research plan. Consent was obtained from every patient prior to participating in the research.

1. History taking.

2. Full physical examination.

3. The severity of cirrhosis was classified in keeping with the Child-Pugh and MELD score.

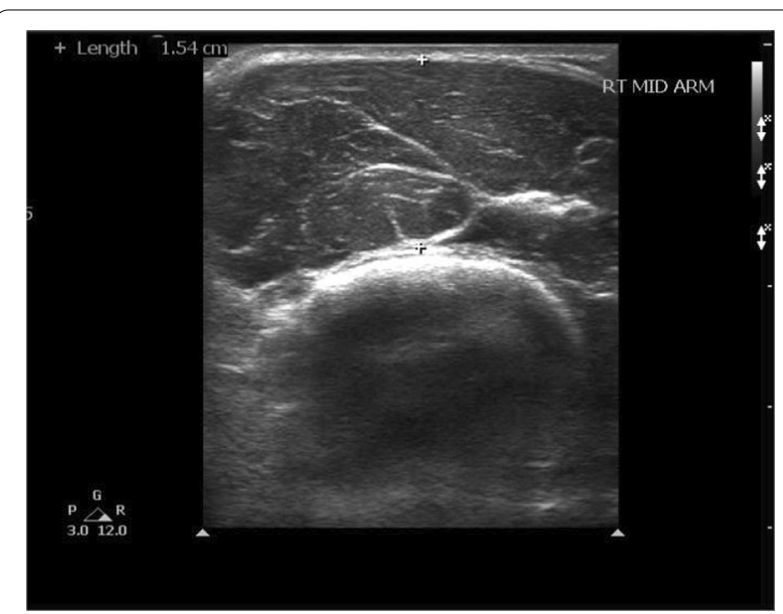

Fig. 1 Ultrasound mid upper arm

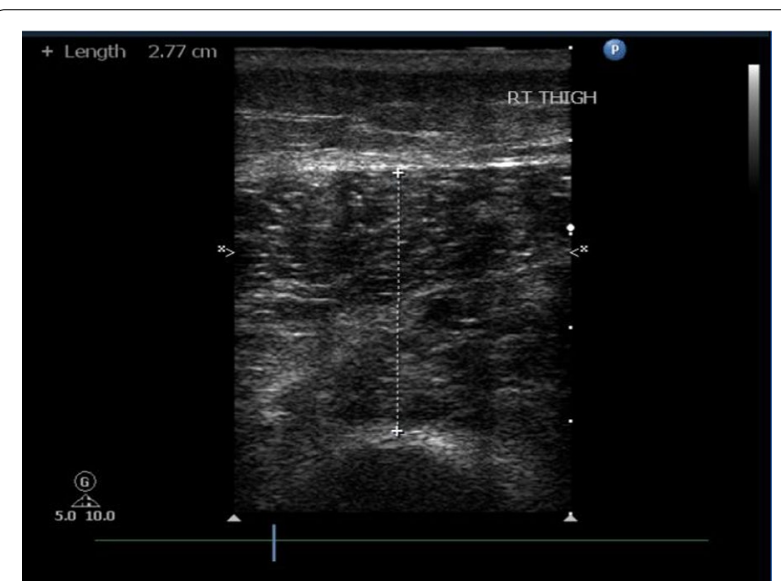

Fig. 2 Ultrasound mid-thigh

\section{Imaging procedure \\ Ultrasound study}

Patient position Supine with flexed relaxed lower limbs and supinated upper limbs.

Ultrasound technique Muscle layer thickness was assessed as a sign of nutritional status and of fat free mass (FFM). It was absolutely measured using B-mode HDI-5000 ultrasound machine (Philips HD11XE) with a broad-band linear array transducer and at a frequency of $5-7.5 \mathrm{MHz}$.

Image acquisition and measurement method The muscle thickness was measured on each side without compression at the following two points: (Figs. 1 and 2). 
1. Anterior mid arm point (Fig. 1): this point was determined at the flexor surface of the arm while the forearm is supinated, corresponding to the point located midway between the tip of the acromion and tip of the olecranon. The thickness of the flexor compartment was measured between the superficial fatmuscle interface and cortex of the humerus.

2. Anterior mid-thigh point (Figs. 2 and 3): with the knee extended, the midway point between the tip of the greater trochanter and also the lateral joint line of the knee was identified and also the thickness of the quadriceps muscle group between the superficial fat-muscle interface and the cortex of the femur was measured anteriorly. After identifying the muscle tissue, the thickness of the quadriceps muscle was obtained by measuring the space between the cortex of the femur and therefore the most superficial muscular fascia (Fig. 2). This measurement site determined using a measuring tape and analyzed so as to seek out the foremost reliable point.

3. Also, quadriceps muscle index was calculated as sum of both muscle thickness RT and LT $\mathrm{cm} /$ height $^{2}\left(\mathrm{~m}^{2}\right)$.

Measurements were performed by Applying maximal compression on the ultrasound probe without inflicting

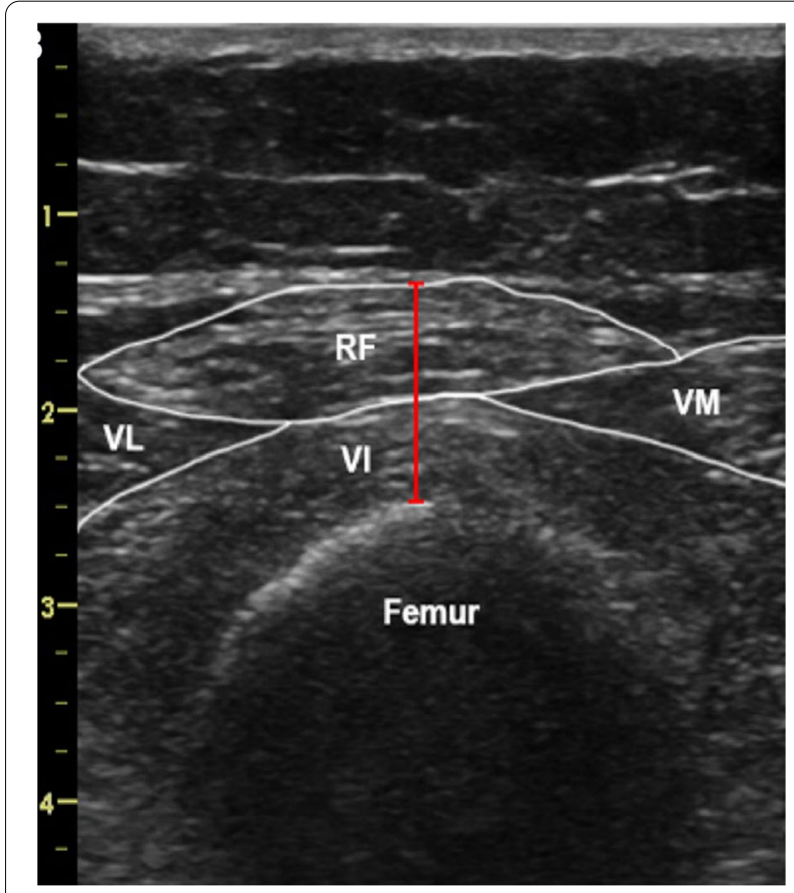

Fig. 3 Ultrasound assessment of the quadriceps femoris muscle thickness. Transverse ultrasound section made by linear probe at the midpoint site. RF: rectus femoris; VL: vastus lateralis; VM: vastus medialis; Vl: vastus intermedius pain, in-order to forestall the underestimation of muscle wasting linked to subcutaneous edema. The effectiveness of the technique had been previously demonstrated in edematous patients.

The scanning procedure itself was deceptively simple; the difficulties raised when it involved interpreting the image to work out muscle thickness at the site(s) of measurement. The interface between fat and muscle is difficult to differentiate, because the resistance of those tissues were somewhat similar, and that they produce a weaker echo compared with one that will include interface with bone tissue.

\section{Assessment of muscle function Hand grip strength (HGS)}

It was measured using the hand grip dynamometry shown in Fig. 4. The patient's data within the type of age and sex were entered then the patient was asked to use his maximum effort to grip both handles of the dynamometer together. The test was repeated for 3 times for every hand separately then the best record value was used as an indicator of patient's performance.

\section{Correlation of the ultrasound analysis and HGS}

Comparative analysis was done between the Ultrasound findings with the muscle function using the Hand Grip strength (HGS), then the results were correlated with

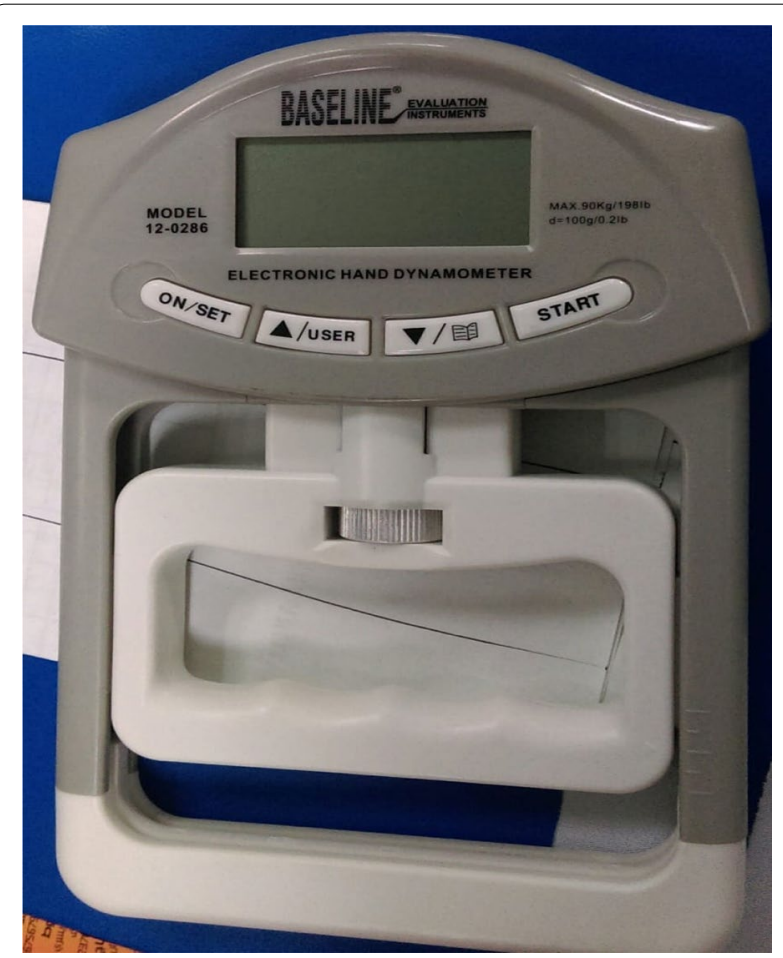

Fig. 4 Hand grip dynamometry 
the normal cut off values for age and sex, as outlined within the results.

\section{Statistical methods}

Data were coded and entered using the statistical package for the Social Sciences (SPSS) version 25 (IBM Corp., Armonk, NY, USA). Data was summarized using mean and variance for quantitative variables and frequencies (number of cases) and relative frequencies (percentages) for categorical variables. Comparisons between groups were done using unpaired t test when comparing 2 groups and analysis of variance (ANOVA) with multiple comparisons post hoc ergo propter hoc test when comparing over 2 groups (Chan 2003a). For comparing categorical data, Chi square $\left(\chi^{2}\right)$ test was performed. Exact test was used instead when the expected frequency is a smaller amount than 5 (Chan 2003b). Correlations between quantitative variables were done using Pearson correlation (Chan 2003c). $P$-values but 0.05 were considered as statistically significant.

\section{Results}

This study was conducted on 101 liver cirrhosis patients who were admitted in internal medicine hospital. In addition to 30 health participants as control group.

According to Child score, patients were divided into 3 groups;

- Child A (6 patients) (Fig. 5),

- Child B (20 patients) (Fig. 6) and
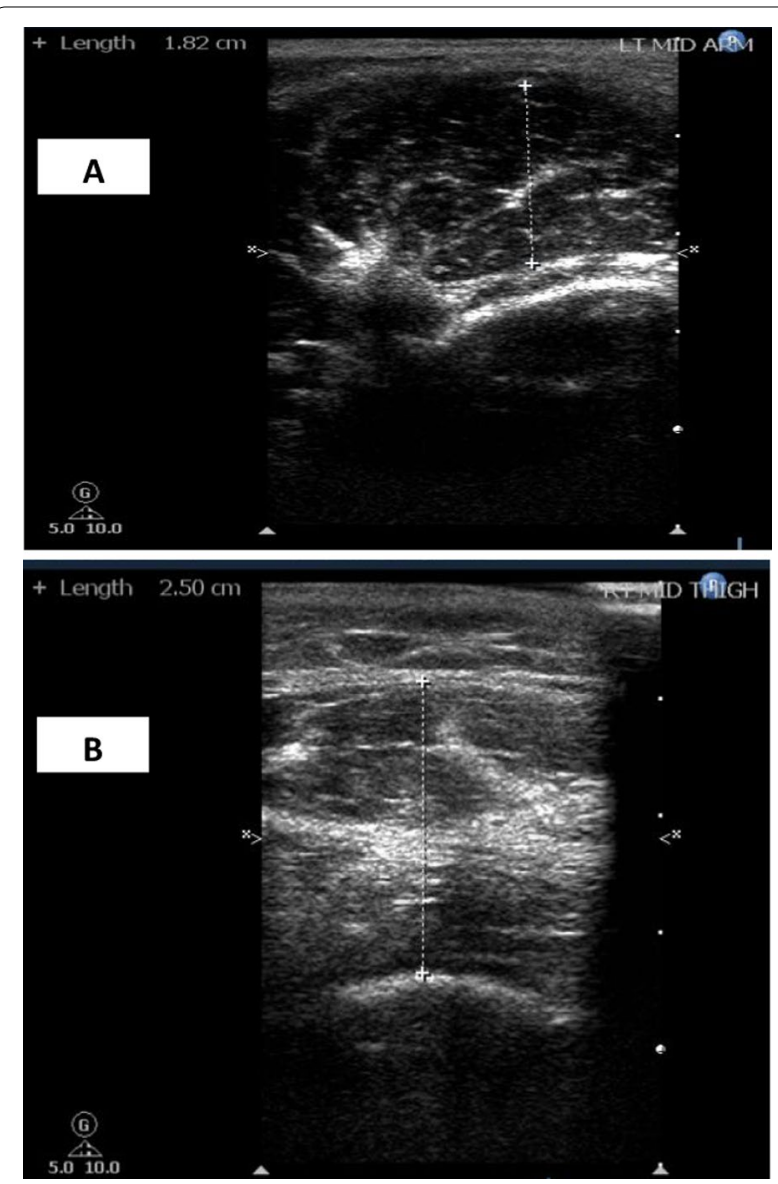

Fig. 6 A, B A male liver cirrhosis patient, 63 years old, HCV positive, BMI: 17.4, NRS 4. His labs: albumin: 2/total bilirubin: 4/INR: 3/ creatinine: 2.4/Child C score 15. HGS: 14.2. A USG mid upper arm of Child C patient, which positively correlated with HGS. B USG mid-thigh of Child C patient, which positively correlated with HGS
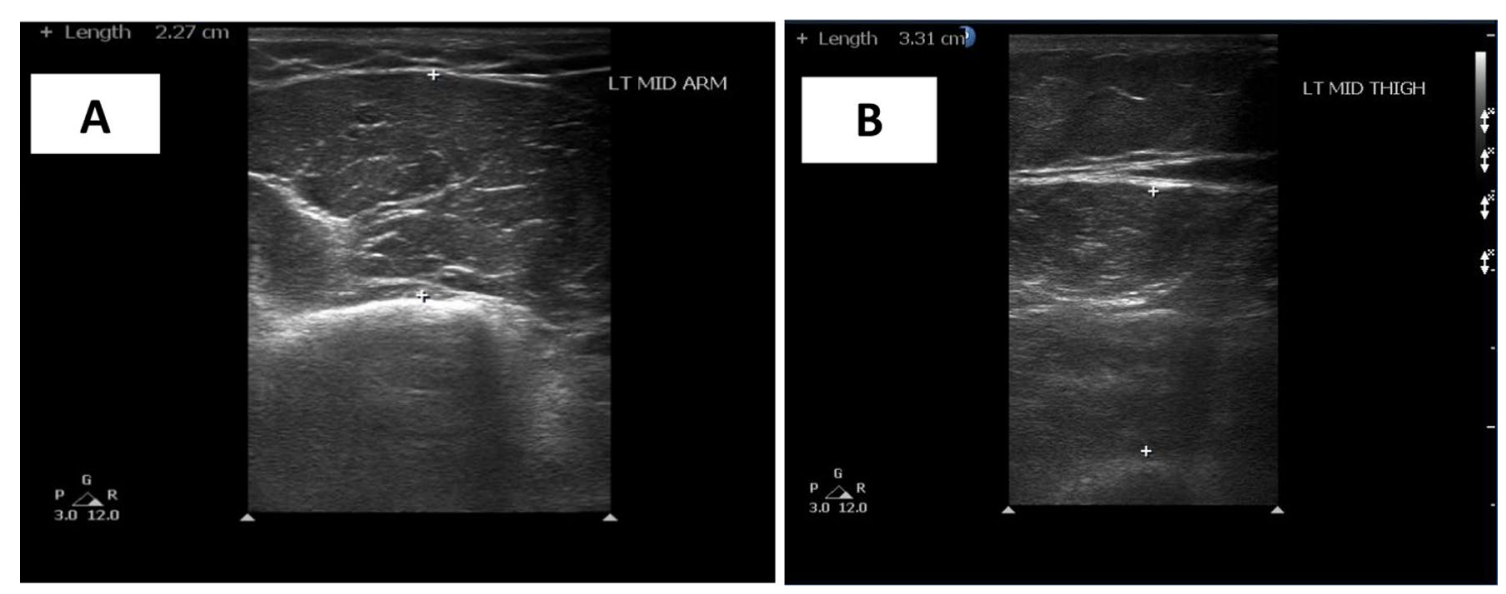

Fig. 5 A, B A male liver cirrhosis patient, 52 years old, HCV positive, BMI: 20, NRS: 2. His labs: albumin: 2.8/total bilirubin: 1/INR: 1.5/creatinine: 0.9/ Child A score 6, HGS: 29.5. A USG mid upper arm of Child A patient which correlated positively with HGS surface area. B USG mid-thigh of Child A patient, which correlated positively with HGS surface area 

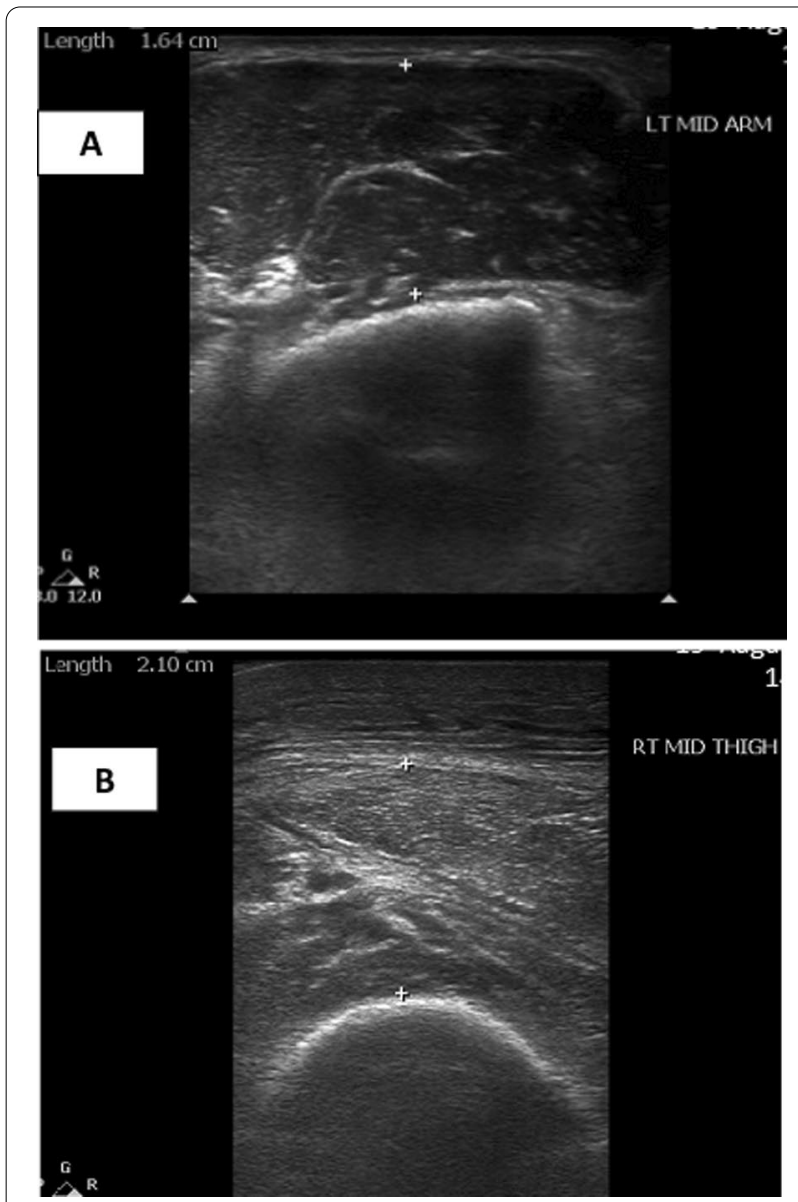

Fig. 7 A, B A male liver cirrhosis patient, 63 years old, HCV positive, BMl: 17.4, NRS 4. His labs: albumin: 2/total bilirubin: 4/INR: 3 / creatinine: $2.4 / C h i l d$ C score 15. HGS: 14.2. A USG mid upper arm of Child C patient, which positively correlated with HGS. B USG mid-thigh of Child $C$ patient, which positively correlated with HGS

- Child C (74 patients) (Fig. 7).

Data of CHILD A and CHILD B patients were analyzed as one group compared to CHILD C patients.

- Control group (Fig. 8) constituted 30 healthy participants with mean age 59.67 ys \pm 8.01 .

The most common reason for liver cirrhosis was $\mathrm{HCV}$.

Table 1 shows the Demographic data of the studied group.

Table 2 shows the relevant Laboratory data of the study group.

Table 3: Model for End-Stage disease (MELD), and length of hospital stay.

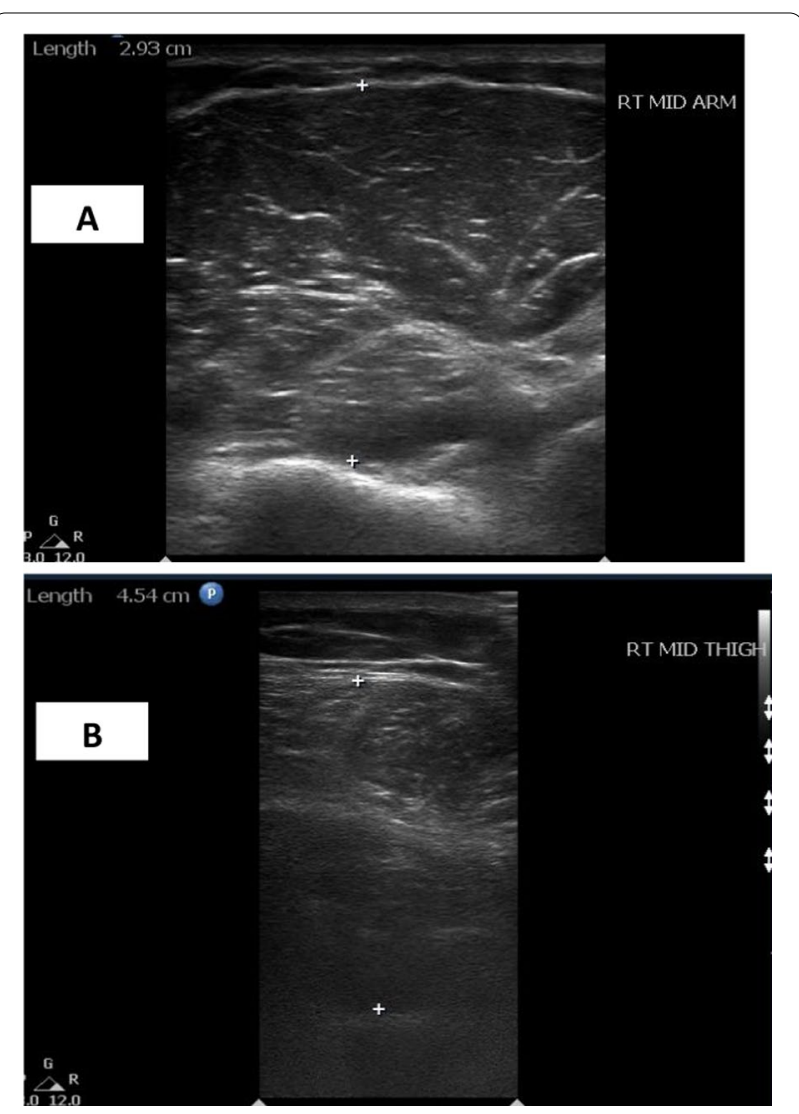

Fig. 8 A, B A male, control subject 63 years old, BMI 23.6, HGS: 35. A USG mid upper arm of control, which positively correlated with HGS. B USG mid-thigh of control, which correlated positively with HGS

Table 1 Demographic data of the studied group

\begin{tabular}{|c|c|c|c|c|}
\hline & & Child A, B & Child C & Control \\
\hline & & $N(26)$ & $N(75)$ & N (30) \\
\hline \multirow[t]{2}{*}{ Age } & $<60$ & 8 & 46 & 14 \\
\hline & $>60$ & 18 & 29 & 16 \\
\hline Sex & Male/female & $19 / 7$ & $36 / 39$ & $16 / 14$ \\
\hline \multirow[t]{4}{*}{ Cause of admission } & Hematemesis & 24 & 48 & \\
\hline & Hepatic coma & 2 & 21 & \\
\hline & SBP & 0 & 5 & \\
\hline & Hepto-renal & 0 & 1 & \\
\hline \multirow[t]{5}{*}{ Etiology } & Hemochromatosis & 0 & 1 & \\
\hline & $\mathrm{HCV}$ & 21 & 65 & \\
\hline & HBV & 0 & 5 & \\
\hline & Bilharziasis & 5 & 3 & \\
\hline & Autoimmune & 0 & 1 & \\
\hline \multirow[t]{3}{*}{ Ascites } & Tense & 0 & 55 & \\
\hline & Moderate & 20 & 20 & \\
\hline & Non & 6 & 0 & \\
\hline \multirow[t]{2}{*}{ Il edema } & Present & 20 & 74 & \\
\hline & Non & 6 & 1 & \\
\hline
\end{tabular}


Table 2 Laboratory data of the studied group

\begin{tabular}{lcc}
\hline & $\begin{array}{c}\text { Child A, B } \\
\text { Mean } \pm \text { SD }\end{array}$ & $\begin{array}{l}\text { Child C } \\
\text { Mean } \pm \text { SD }\end{array}$ \\
\hline Age (yrs) & $61.81 \pm 5.82$ & $58.63 \pm 7.33$ \\
FBS (mmol) & $133.23 \pm 34.94$ & $117.59 \pm 32.92$ \\
Albumin $(\mathrm{mg} / \mathrm{dl})$ & $2.70 \pm 0.34$ & $2.06 \pm 0.32$ \\
Bilirubin $(\mathrm{mg} / \mathrm{dl})$ & $0.97 \pm 0.47$ & $3.59 \pm 2.97$ \\
INR & $1.71 \pm 0.16$ & $2.35 \pm 0.44$ \\
Creatinine $(\mathrm{mg} / \mathrm{dl})$ & $0.97 \pm 0.12$ & $1.42 \pm 0.55$ \\
\hline
\end{tabular}

Table 3 Model for end-stage liver disease (MELD), and length of hospital stay

\begin{tabular}{lrrr}
\hline & $\begin{array}{l}\text { Child A, B } \\
\text { Mean } \pm \text { SD }\end{array}$ & $\begin{array}{l}\text { Child C } \\
\text { Mean } \pm \text { SD }\end{array}$ & P value \\
\hline MELD & $11.58 \pm 3.19$ & $22.41 \pm 6.71$ & $<0.001$ \\
$\begin{array}{l}\text { Length of hospital } \\
\text { stay (days) }\end{array}$ & $3.38 \pm 0.80$ & $7.08 \pm 2.53$ & $<0.001$ \\
\hline
\end{tabular}

Table 4 Hand grip and anthropometric measures

\begin{tabular}{lllll}
\hline & Group & & \multirow{2}{*}{ P value } \\
\cline { 2 - 4 } & Child A,B & Child C & Control & \\
& Mean \pm SD & Mean \pm SD & Mean \pm SD & \\
\hline Dry wt (kg) & $61.69 \pm 7.54$ & $51.73 \pm 5.22$ & $84.52 \pm 12.45$ & $<0.001$ \\
BMl & $20.59 \pm 1.69$ & $18.27 \pm 0.80$ & $28.21 \pm 4.89$ & $<0.001$ \\
MUAC & $28.31 \pm 3.16$ & $21.28 \pm 3.47$ & $33.45 \pm 2.52$ & $<0.001$ \\
Hand grip & $22.78 \pm 6.36$ & $14.88 \pm 5.13$ & $29.15 \pm 7.50$ & $<0.001$ \\
\hline
\end{tabular}

Table 5 Posthoc pairwise comparison ( $P$ value between each 2 groups)

\begin{tabular}{lccc}
\hline & $\begin{array}{l}\text { Child A,B versus } \\
\text { Child C }\end{array}$ & $\begin{array}{l}\text { Child A,B versus } \\
\text { control }\end{array}$ & $\begin{array}{l}\text { Child C } \\
\text { versus } \\
\text { control }\end{array}$ \\
\hline Age & 0.166 & 0.813 & 1.000 \\
Dry wt & $<0.001$ & $<0.001$ & $<0.001$ \\
BMl & $<0.001$ & $<0.001$ & $<0.001$ \\
MUAC(CM) & $<0.001$ & $<0.001$ & $<0.001$ \\
Hand grip & $<0.001$ & $<0.001$ & $<0.001$ \\
\hline
\end{tabular}

Table 4 Hand grip and Anthropometric measures.

Table 5 Posthoc pairwise comparison ( $\mathrm{P}$ value between each 2 groups).

The hand grip and anthropometric measures in Child groups namely dry weight, BMI, Mid upper arm circumference (MUAC) differed significantly between patients and control in addition as between both groups of patients $(P$ value $<0.001)$.

\section{Peripheral muscle assessment by ultrasound}

Muscle thickness at mid-upper arm, mid-thigh and quadriceps muscle index all decreased significantly in liver cirrhosis patients compared to control group, as well as between both groups of patients according to Child score.

The presence of significant difference between muscle thickness in patients group (A\&B) versus controls indicates that wasting starts early within the disease course.

Table 6 Ultrasound mid upper arm, mid-thigh muscle thickness and quadriceps muscle index.

Table 7 Correlation between ultrasound parameters, (Child, MELD) scores, hand grip, and length of hospital stay.

$\neg$ Cut off values for male muscle layer thickness by ultrasound (Table 8).

$\neg$ We divided our patients into weak and non-weak in line with muscle function using Foundation for National Institutes of Health (FNIH), with cut-off values $(<26 \mathrm{~kg}$ in male and $<16 \mathrm{~kg}$ in female) on ROC curve (Studenski et al. 2014), to detect cut off value of ultrasound muscle thickness (mid upper arm, mid-thigh and quadriceps index) and cut off value of psoas muscle index to detect sarcopenic patients.

$\neg$ In our group of patients nearly $86.1 \%$ of our patients were sarcopenic evidenced by HGS.

$\neg$ They are illustrated in Table 8 with good sensitivity ranging between $70.5 .5 \%$ to $79.5 \%$ and good specificity ranging between $90.9 \%$ and $100 \%$.

$\neg$ Cut off values for female muscle layer thickness by ultrasound.

They are illustrated in Table 9 with good sensitivity ranging between 88.4 and $100 \%$ and good specificity ranging between 97.7 and $100 \%$.

$\neg$ Cut off values for male quadriceps thickness index Table 10 .

It is illustrated in Figs. 9 and 11 with good sensitivity $79.5 \%$ and good specificity $90.9 \%$.

$\neg$ Cut off values for female quadriceps thickness index Table 11:

It is illustrated in Figs. 10 and 12 with good sensitivity 97.7\% and good specificity 100\% (Figs. 11 and 12).

$\neg$ Correlation between ultrasound muscle thickness, quadriceps muscle index, anthropometric measurement and laboratory results (Table 12).

In general the ultrasound mid upper arm \& thigh and quadriceps muscle index on both sides with mean RT and LT measure, showed significant positive relation with anthropometric measurement (dry wt, BMI, MUAC, 
Table 6 Ultrasound mid upper arm, mid-thigh muscle thickness and quadriceps muscle index

\begin{tabular}{|c|c|c|c|c|}
\hline \multirow[t]{3}{*}{$(\mathrm{cm})$} & \multicolumn{3}{|l|}{ Group } & \multirow{3}{*}{$\begin{array}{l}< \\
P \text { value }\end{array}$} \\
\hline & \multirow{2}{*}{$\begin{array}{l}\text { Child A, B } \\
\text { Mean } \pm \text { SD }\end{array}$} & \multirow{2}{*}{$\begin{array}{l}\text { Child C } \\
\text { Mean } \pm \text { SD }\end{array}$} & \multirow{2}{*}{$\begin{array}{l}\text { Control } \\
\text { Mean } \pm \text { SD }\end{array}$} & \\
\hline & & & & \\
\hline RT mid arm USG & $1.98 \pm 0.30$ & $1.51 \pm 0.26$ & $2.69 \pm 0.47$ & $<0.001$ \\
\hline LT mid arm USG & $2.02 \pm 0.30$ & $1.54 \pm 0.25$ & $2.73 \pm 0.51$ & $<0.001$ \\
\hline Mean RT\&LT mid arm USG & $2.00 \pm 0.29$ & $1.53 \pm 0.25$ & $2.71 \pm 0.49$ & $<0.001$ \\
\hline RT mid-thigh USG & $2.89 \pm 0.34$ & $2.29 \pm 0.45$ & $3.81 \pm 0.50$ & $<0.001$ \\
\hline LT mid-thigh USG & $2.96 \pm 0.34$ & $2.30 \pm 0.46$ & $3.86 \pm 0.56$ & $<0.001$ \\
\hline Mean RT\&LT mid-thigh USG & $2.93 \pm 0.33$ & $2.30 \pm 0.45$ & $3.83 \pm 0.53$ & $<0.001$ \\
\hline \multirow[t]{2}{*}{ Quadriceps thickness index $\left(\mathrm{cm} / \mathrm{m}^{2}\right)$} & $1.69 \pm 0.17$ & $1.36 \pm 0.26$ & $2.20 \pm 0.28$ & $<0.001$ \\
\hline & \multicolumn{2}{|c|}{ Child A, B versus Child C } & Child A, B versus control & $\begin{array}{l}\text { Child C } \\
\text { versus } \\
\text { control }\end{array}$ \\
\hline RT mid arm USG & $<0.001$ & & $<0.001$ & $<0.001$ \\
\hline LT mid arm USG & $<0.001$ & & $<0.001$ & $<0.001$ \\
\hline Mean RT\&LT mid arm USG & $<0.001$ & & $<0.001$ & $<0.001$ \\
\hline RT mid-thigh USG & $<0.001$ & & $<0.001$ & $<0.001$ \\
\hline LT mid-thigh USG & $<0.001$ & & $<0.001$ & $<0.001$ \\
\hline Mean RT\&LT mid-thigh USG & $<0.001$ & & $<0.001$ & $<0.001$ \\
\hline USG quadriceps thickness index & $<0.001$ & & $<0.001$ & $<0.001$ \\
\hline
\end{tabular}

Posthoc pairwise comparison ( $P$ value between each 2 groups)

Table 7 Correlation between ultrasound parameters, (Child, MELD, and NRS) scores, hand grip, and length of hospital stay

\begin{tabular}{|c|c|c|c|c|c|c|c|}
\hline & & Child & MELD & NRS & MUAC & Hand grip & $\begin{array}{l}\text { Length of } \\
\text { hospital stay } \\
\text { (days) }\end{array}$ \\
\hline \multirow[t]{3}{*}{ RT mid arm USG } & r & -0.629 & -0.516 & -0.737 & 0.960 & 0.905 & -0.522 \\
\hline & $P$ value & $<0.001$ & $<0.001$ & $<0.001$ & $<0.001$ & $<0.001$ & $<0.001$ \\
\hline & $\mathrm{N}$ & 101 & 101 & 101 & 101 & 101 & 101 \\
\hline \multirow[t]{3}{*}{ LT mid arm USG } & r & -0.654 & -0.529 & -0.756 & 0.944 & 0.893 & -0.553 \\
\hline & $P$ value & $<0.001$ & $<0.001$ & $<0.001$ & $<0.001$ & $<0.001$ & $<0.001$ \\
\hline & $\mathrm{N}$ & 101 & 101 & 101 & 101 & 101 & 101 \\
\hline \multirow[t]{3}{*}{ Mean RT\&LT mid arm USG } & r & -0.647 & -0.528 & -0.753 & 0.961 & 0.908 & -0.543 \\
\hline & $P$ value & $<0.001$ & $<0.001$ & $<0.001$ & $<0.001$ & $<0.001$ & $<0.001$ \\
\hline & $\mathrm{N}$ & 101 & 101 & 101 & 101 & 101 & 101 \\
\hline \multirow[t]{3}{*}{ RT mid-thigh USG } & r & -0.597 & -0.500 & -0.707 & 0.893 & 0.890 & -0.523 \\
\hline & $P$ value & $<0.001$ & $<0.001$ & $<0.001$ & $<0.001$ & $<0.001$ & $<0.001$ \\
\hline & $\mathrm{N}$ & 101 & 101 & 101 & 101 & 101 & 101 \\
\hline \multirow[t]{3}{*}{ LT mid-thigh USG } & r & -0.613 & -0.534 & -0.691 & 0.874 & 0.863 & -0.568 \\
\hline & $P$ value & $<0.001$ & $<0.001$ & $<0.001$ & $<0.001$ & $<0.001$ & $<0.001$ \\
\hline & $\mathrm{N}$ & 101 & 101 & 101 & 101 & 101 & 101 \\
\hline \multirow[t]{3}{*}{ Mean RT\&LT mid- thigh USG } & $\mathrm{R}$ & -0.613 & -0.524 & -0.707 & 0.894 & 0.887 & -0.553 \\
\hline & $P$ value & $<0.001$ & $<0.001$ & $<0.001$ & $<0.001$ & $<0.001$ & $<0.001$ \\
\hline & $\mathrm{N}$ & 101 & 101 & 101 & 101 & 101 & 101 \\
\hline \multirow[t]{3}{*}{ US Quadriceps thickness index } & $\mathrm{R}$ & -0.602 & -0.532 & -0.661 & 0.838 & 0.812 & -0.553 \\
\hline & $P$ value & $<0.001$ & $<0.001$ & $<0.001$ & $<0.001$ & $<0.001$ & $<0.001$ \\
\hline & $\mathrm{N}$ & 101 & 101 & 101 & 101 & 101 & 101 \\
\hline
\end{tabular}


Table 8 Cut off values for male muscle layer thickness

\begin{tabular}{|c|c|c|c|c|c|c|c|}
\hline \multirow[t]{2}{*}{$(\mathrm{cm})$} & \multirow{2}{*}{$\begin{array}{l}\text { Area under } \\
\text { the curve }\end{array}$} & \multirow[t]{2}{*}{$P$ value } & \multicolumn{2}{|c|}{ 95\% Confidence interval } & \multirow[t]{2}{*}{ Cut off } & \multirow[t]{2}{*}{ Sensitivity \% } & \multirow[t]{2}{*}{ Specificity \% } \\
\hline & & & Lower bound & Upper bound & & & \\
\hline Mean RT and LT mid arm USG & 0.921 & $<0.001$ & 0.848 & 0.995 & 1.9175 & 70.5 & 100 \\
\hline Mean RT and LT mid- thigh USG & 0.945 & $<0.001$ & 0.887 & 1.000 & 2.925 & 81.8 & 100 \\
\hline USG Quadriceps thickness index $\left(\mathrm{cm} / \mathrm{m}^{2}\right)$ & 0.908 & $<0.001$ & 0.824 & 0.992 & 1.675 & 79.5 & 90.9 \\
\hline
\end{tabular}

Table 9 Cut off values for female muscle layer thickness

\begin{tabular}{|c|c|c|c|c|c|c|c|}
\hline \multirow[t]{2}{*}{$(\mathrm{cm})$} & \multirow{2}{*}{$\begin{array}{l}\text { Area under } \\
\text { the curve }\end{array}$} & \multirow[t]{2}{*}{$P$ value } & \multicolumn{2}{|c|}{ 95\% Confidence interval } & \multirow[t]{2}{*}{ Cut off } & \multirow[t]{2}{*}{ Sensitivity \% } & \multirow[t]{2}{*}{ Specificity \% } \\
\hline & & & Lower Bound & Upper Bound & & & \\
\hline Mean RT\&LT mid arm USG & 0.946 & 0.011 & 0.869 & 1.000 & 1.5825 & 88.4 & 100 \\
\hline Mean RT\&LT mid- thigh USG & 0.992 & 0.005 & 0.969 & 1.000 & 2.61 & 97.7 & 100 \\
\hline USG Quadriceps thickness index $\left(\mathrm{cm} / \mathrm{m}^{2}\right)$ & 0.984 & 0.005 & 0.950 & 1.000 & 1.585 & 97.7 & 100 \\
\hline
\end{tabular}

Table 10 Cut off values for male quadriceps thickness index

\begin{tabular}{|c|c|c|c|c|c|c|}
\hline \multirow[t]{2}{*}{ Area under the curve } & \multirow[t]{2}{*}{$P$ value } & \multicolumn{2}{|c|}{ 95\% Confidence interval } & \multirow[t]{2}{*}{ Cut off $\left(\mathrm{cm} / \mathrm{m}^{2}\right)$} & \multirow[t]{2}{*}{ Sensitivity \% } & \multirow[t]{2}{*}{ Specificity \% } \\
\hline & & Lower Bound & Upper Bound & & & \\
\hline 0.908 & $<0.001$ & 0.824 & 0.992 & 1.675 & 79.5 & 90.9 \\
\hline
\end{tabular}

Hand grip), and laboratory results ( albumin, bilirubin, INR, creatinine $)$ with $(P$ value $<0.001)$.

\section{Discussion}

Severe muscle wasting, or sarcopenia is the commonest and often most hidden complication in patients with cirrhosis, which negatively impact survival, quality of life, and response to stressor, like infections and surgeries. Patients with malnutrition and/or sarcopenia have longer hospital stay and increased in-hospital mortality [15].

Sarcopenia is related to high morbidity and mortality in healthy older adults and patients with chronic diseases [15] and is a common risk factor for frailty, falls, and fractures. The tests as CT and DEXA are costly, of limited availability, require trained personnel, and expose the patient to radiation. Therefore, it is recommended to have new methods developed to facilitate the diagnosis of sarcopenia [10]. The prevalence of sarcopenia among patients with early-stage cirrhosis is of clinical importance because its relation to increase mortality and complications [5].

Our study demonstrated that US can be used as a reliable and valid method for the evaluation of muscle mass by measuring the muscle-CSA in cirrhotic patients. Our results demonstrated that sarcopenia can be diagnosed with a rapid imaging test that's simple to perform, easily interpreted and available at the bedside.
Ultrasonography (USG) is emerging as a promising tool in measuring muscle at the bedside by quantifying the layer thickness of a muscle or muscle group of interest as an indicator of nutritional status [17]. Quadriceps muscle thickness detection by ultrasound has been recently proposed as a better bedside tool to assess sarcopenia [18].

In our study ultrasound mid upper arm, thigh and quadriceps muscle index showed significant correlational statistics $(P$ value $>0.001)$ with disease severity assessed by (Child, MELD) scores. Also, ultrasound parameters showed direct correlation with muscle function assessment by HGS. So, consequently, the lower the muscle thickness (mid upper arm, quadriceps muscle) the more disease severity, and the more the patient was malnourished and also the lower HGS.

In agreement with our study [19] showed a prospective study, which was conducted using ultrasound measurement of quadriceps muscle layer thickness (QMLT) in 93 adult patients assessed for liver transplant.

These measures were compared to MELD scores, and HGS. Lower QMLT was related to decreased HGS, with $(P=0.001)$. Also results the same as our study which had person correlation (males) of QMLT with Na-MELD $(P=0.001)$ and our study had significant indirect correlation between QMLT and MELD.

They found a direct correlation between SMI and TPI $(P<0.001)$. The AUC for TPI considering sarcopenia by 


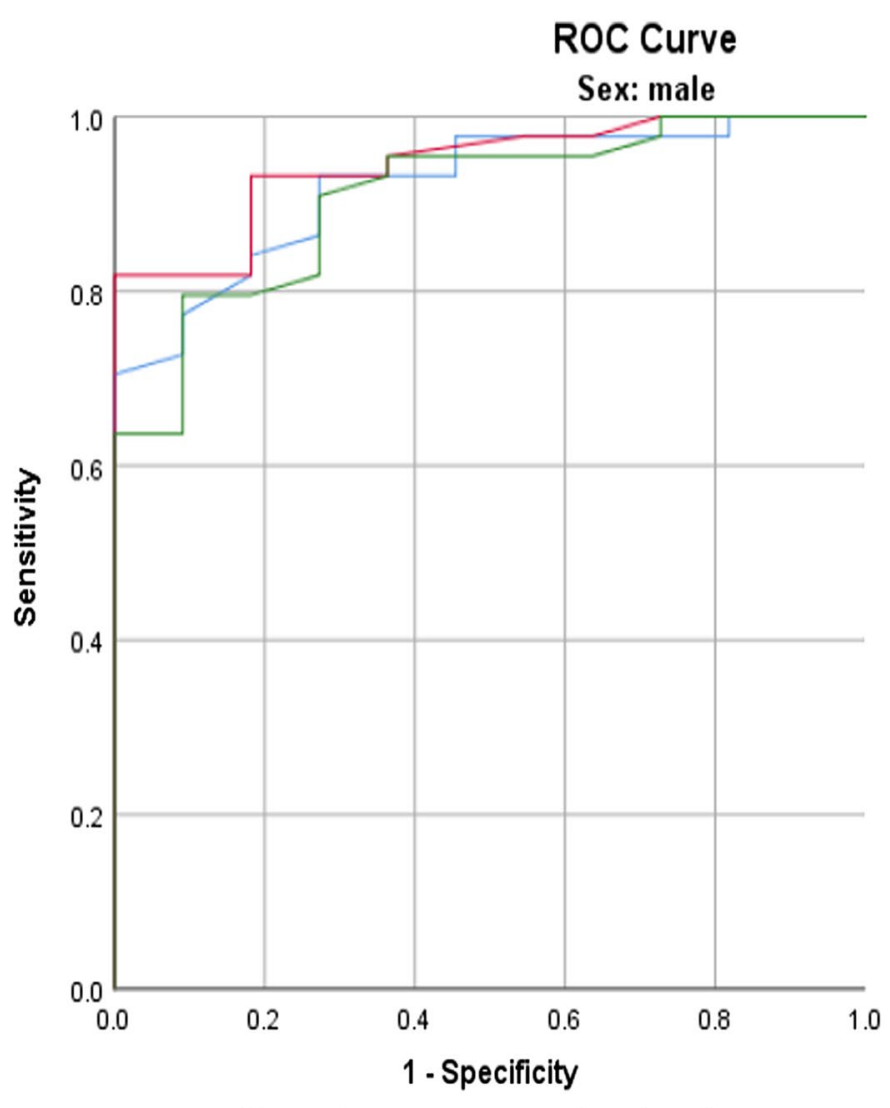

\section{Source of the Curve}

- US average mid arm

- US mid average thigh US Quadricepes thickness index

Diagonal segments are produced by ties.

Fig. 9 Cut off values for female muscle layer thickness

Table 11 Cut off values for female quadriceps thickness index

\begin{tabular}{|c|c|c|c|c|c|c|}
\hline \multirow[t]{2}{*}{ Area under the curve } & \multirow[t]{2}{*}{$P$ value } & \multicolumn{2}{|c|}{ 95\% Confidence interval } & \multirow[t]{2}{*}{ Cut off $\left(\mathrm{cm} / \mathrm{m}^{2}\right)$} & \multirow[t]{2}{*}{ Sensitivity \% } & \multirow[t]{2}{*}{ Specificity \% } \\
\hline & & Lower bound & Upper bound & & & \\
\hline 0.984 & 0.005 & 0.950 & 1.000 & 1.585 & 97.7 & 100 \\
\hline
\end{tabular}

SMI was 0.79.) and this correlation accept as true with our study but we used quadriceps thickness index without pressure and we found a correlation between psoas muscle index and quadriceps thickness index with high sensitivity and specificity on ROC curve with AUC 0.9.

To our greatest knowledge we used muscle function (cut off value of hand grip $<26 \mathrm{~kg}$ in male and $<16 \mathrm{~kg}$ in female to detect stop value of muscle thickness by ultrasound mid upper arm, mid-thigh and quadriceps index on ROC curve. It showed high sensitivity and specificity. With AUC about 0.9 .

HGS is considered as a noninvasive, simple and quick method can be employable in clinical and epidemiological studies [20,21].
This study [22] suggested that in early stages of cirrhosis, muscle strength measured by HGS should be accustomed to evaluate for malnutrition and sarcopenia. Among patients with cirrhosis, $88 \%$ were ChildPugh A and only $12 \%$ were Child-Pugh B evaluated for handgrip strength (HGS) in out-patients clinic $(n=50)$ and followed for 1 year to verify the incidence of major complications, the requirement for transplantation, and death. Among these, prevalence of malnutrition was $63 \%$ by HGS $(P<0.05)$ and this resonates with our study that HGS significantly correlated with NRS and low HGS started early even in Child A. HGS, predicted a poorer clinical outcome in patients with cirrhosis because major complications developed in $65.5 \%$ of malnourished 


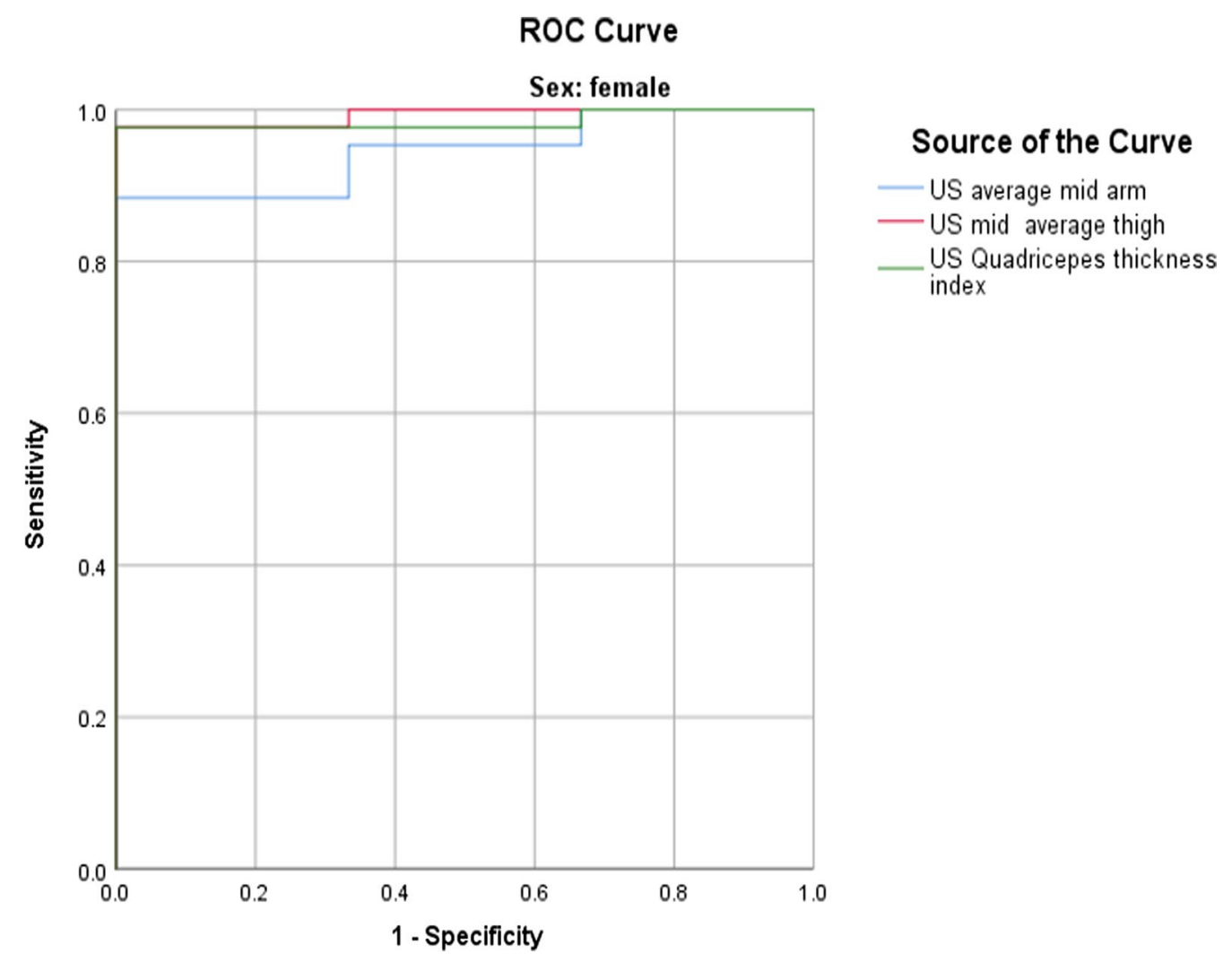

Fig. 10 Cut off value of female ultrasound muscle thickness

sarcopenic patients versus $11.8 \%$ of well-nourished ones $(P<0.05)$.

HG was the sole technique that predicted a major incidence of major complications in $1 \mathrm{y}$ in undernourished cirrhotic patients so HGS is easy noninvasive method is employed in an early stage like in Child A to detect sarcopenia and to forestall complications.

In our group of patients nearly $86.1 \%$ of our patients were sarcopenic as evidenced by hand grip strength using FNIH bring to a halt value $(<26 \mathrm{~kg}$ in male and $<16 \mathrm{~kg}$ in female) [23], being worst with increasing severity of the disease.

In our study, HGS was positively correlated with anthropometric measurement NRS for nutritional assessment, and negatively correlated enceinte score, and with mortality risk (MELD score) with ( $P$ value $>0.001)$.

In agreement with [24] study which was supported by the PG-SGA and NRS 2002, which assessed malnutrition and screen for nutritional risk, respectively. They found a powerful correlation between HGS and nutritional status in elderly inpatients at hospital admission, lower HGS was related to malnutrition nutritional risk and sarcopenia status with $(P$ value $<0.001)$, and HGS was a stronger predictor of nutritional status.
Also, another study [25]. found that hand grip strength correlated with nutritional status, which was measured employing a Patient-Generated Subjective Global Assessment (PG-SGA) questionnaire, and these factors are often used as nutritional status predictors and nutritional status changes $(P<0.01, r=0.292)$. Most subjects were observed prospectively for 3 weeks. Changes in hand grip strength correlated with nutritional status changes $(P=0.002$ and $r=0.767)$.

Affirmed by the study [26], 80 patients with alcoholic disease with a mean MELD score of $10.50 \pm 2.67$ were followed for 3 months. Eleven patients died during follow-up. A significant correlation was noted between HGS and Child-Pugh score $(P \leq 00,012)$ and MELD score $(P \leq 0001)$. Mean HGS was significantly lower in patients who died during follow-up $(18.04 \pm 4.82$ in deceased vs. $24.23 \pm 5.86$ in survivors, $P=0001)$.

Another study showed similar results, which prospectively evaluated 100 patients. All were also assessed for the severity of liver cirrhosis and mortality risk by (Child\& MELD) scores and HGS. HGS mean values were significantly lower, with increased cirrhosis severity as estimated by (Child and MELD) scores with ( $P$ value $=0.012)[27]$. 


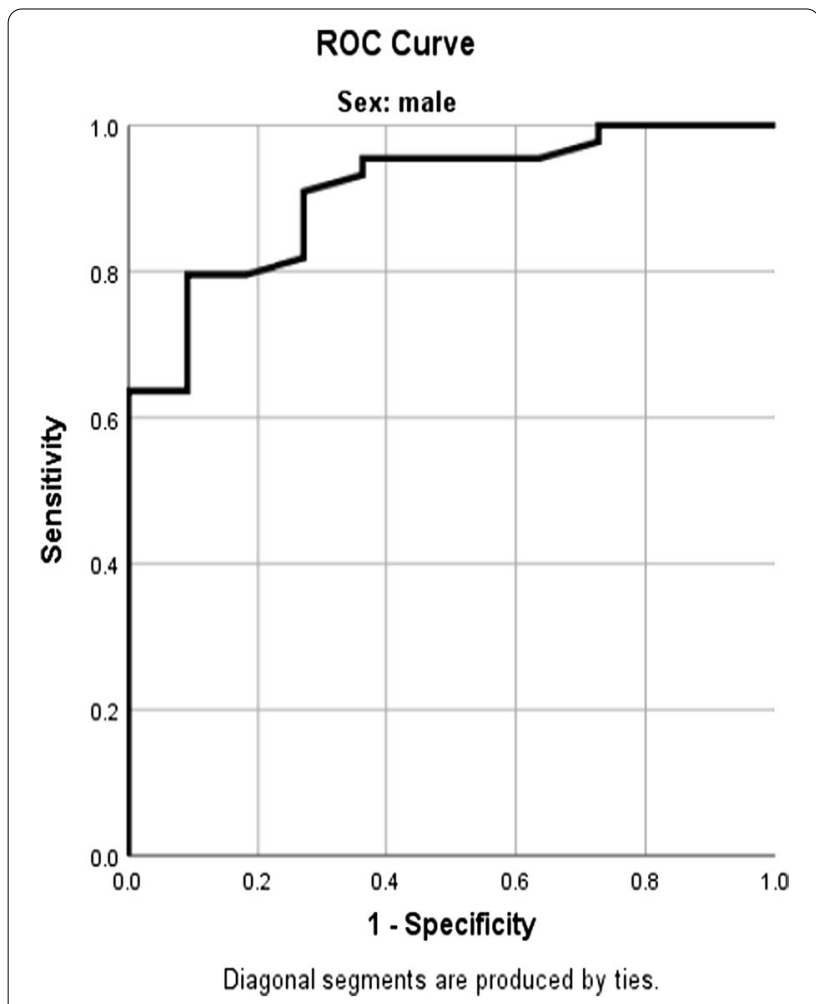

Fig. 11 Cut off value of male quadriceps index

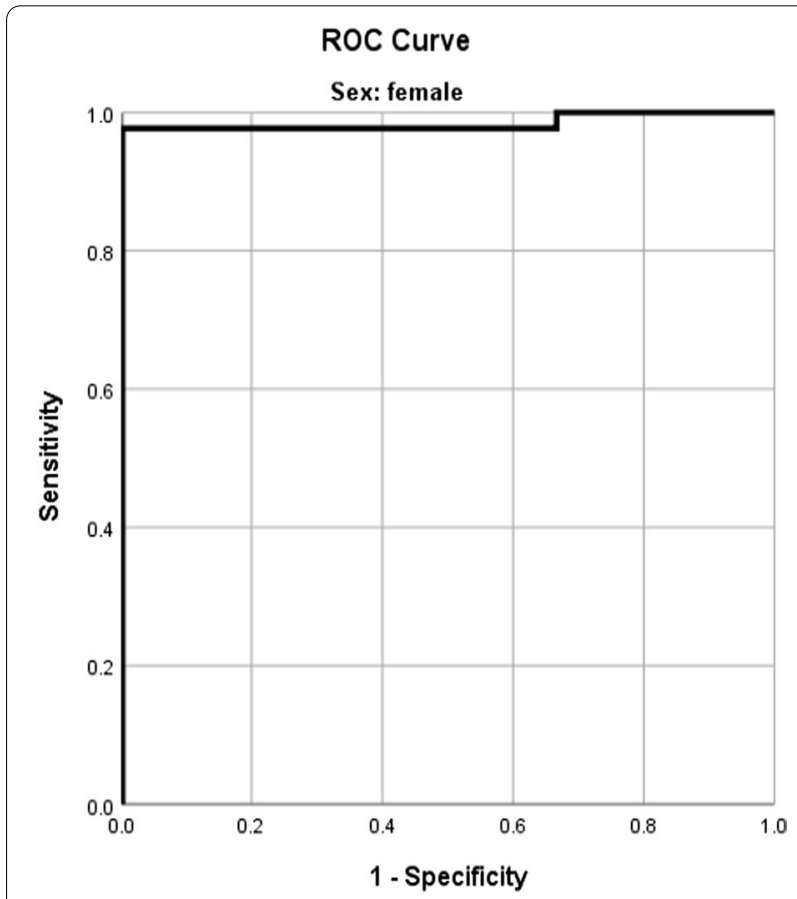

Fig. 12 Cut off value of female quadriceps index
In contrary to our results, a study by [28] showed no correlation between HGS and Child classification. They included patients who were mostly with compensated liver cirrhosis (91 of 129 patients were Child A, 27 were Child B, and only 9 were Child C). They tested the non-dominant hand and showed that HGS failed to significantly decreased with increased severity of liver cirrhosis with $(P=0510)$.

The discrepancy between the results of those studies (ours, 28, 27 vs. 29.) may come from the actual fact that HGS was tested within the dominant hand, while [28] examined the non-dominant hands.

One study agreed with the study [29], which was prospective analysis conducted on 176 hospitalized patients with cirrhosis, which found a mid-arm circumference $(\mathrm{cm})$ significantly direct correlation with the severity of the disease. $4 \%$ of their patients were Child-Pugh C and 59\% had ascites.

\section{Limitations}

1. The foremost patients admitted in our hospital who have complications like hematemesis, coma, $\mathrm{SBP}$, et al. because of hepatic decompensation are of CHILD C group so patients of CHILD A and B patients are less in number. And most of CHILD C group patients have critical case so we stabilized the patients first.

2. Overflow of patients within all specialties in our hospital makes using ultrasound for limited number of hepatic patients not all unlike other institutes which are specialized in hepatology.

3. There are no normal values for muscle thickness among Egyptians (normal general population) by ultrasound measures.

4. We didn't follow up patients after discharge for quality of life, readmissions and post hospital mortality.

5. Significant lower leg edema may present a limitation in ultrasound assessment of thigh muscle.

\section{Strengths}

1. We used US to assess muscle thickness also we used HGS to assess muscle function.

2. To our greatest knowledge this is often the primary study using HGS to line cutoff value of muscle thickness by US.

\section{Conclusion}

The assessment by ultrasound of the quadriceps muscle thickness likewise because the mid arm point reveals good intra- and inter-observer reliability and 
Table 12 Correlation between ultrasound muscle thickness quadriceps muscle index and anthropometric measurement and laboratory results

\begin{tabular}{|c|c|c|c|c|c|c|c|c|c|c|c|}
\hline & & Age & Dry wt & HT & BMI & FBS & Alb & Bil & INR & Urea & Creat \\
\hline \multirow[t]{3}{*}{ RT mid arm USG } & $\mathrm{R}$ & -0.220 & 0.817 & 0.534 & 0.802 & 0.026 & 0.527 & -0.373 & -0.525 & -0.009 & -0.309 \\
\hline & $P$ value & 0.027 & $<0.001$ & $<0.001$ & $<0.001$ & 0.798 & $<0.001$ & $<0.001$ & $<0.001$ & 0.927 & 0.002 \\
\hline & $\mathrm{N}$ & 101 & 101 & 101 & 101 & 101 & 101 & 101 & 101 & 101 & 101 \\
\hline \multirow[t]{3}{*}{ LT mid arm USG } & $\mathrm{R}$ & -0.198 & 0.833 & 0.552 & 0.805 & 0.007 & 0.539 & -0.362 & -0.526 & 0.032 & -0.319 \\
\hline & $P$ value & 0.047 & $<0.001$ & $<0.001$ & $<0.001$ & 0.944 & $<0.001$ & $<0.001$ & $<0.001$ & 0.754 & 0.001 \\
\hline & N & 101 & 101 & 101 & 101 & 101 & 101 & 101 & 101 & 101 & 101 \\
\hline \multirow[t]{3}{*}{ Mean RT\&LT mid arm USG } & $\mathrm{R}$ & -0.211 & 0.833 & 0.548 & 0.811 & 0.017 & 0.538 & -0.371 & -0.530 & 0.011 & -0.317 \\
\hline & $P$ value & 0.034 & $<0.001$ & $<0.001$ & $<0.001$ & 0.869 & $<0.001$ & $<0.001$ & $<0.001$ & 0.912 & 0.001 \\
\hline & $N$ & 101 & 101 & 101 & 101 & 101 & 101 & 101 & 101 & 101 & 101 \\
\hline \multirow[t]{3}{*}{ RT mid-thigh USG } & $\mathrm{R}$ & -0.189 & 0.782 & 0.543 & 0.740 & 0.070 & 0.499 & -0.401 & -0.464 & -0.041 & -0.326 \\
\hline & $P$ value & 0.058 & $<0.001$ & $<0.001$ & $<0.001$ & 0.485 & $<0.001$ & $<0.001$ & $<0.001$ & 0.683 & 0.001 \\
\hline & $\mathrm{N}$ & 101 & 101 & 101 & 101 & 101 & 101 & 101 & 101 & 101 & 101 \\
\hline \multirow[t]{3}{*}{ LT mid- thigh USG } & $\mathrm{R}$ & -0.126 & 0.735 & 0.478 & 0.733 & -0.005 & 0.476 & -0.462 & -0.502 & 0.013 & -0.347 \\
\hline & $P$ value & 0.210 & $<0.001$ & $<0.001$ & $<0.001$ & 0.960 & $<0.001$ & $<0.001$ & $<0.001$ & 0.895 & $<0.001$ \\
\hline & $\mathrm{N}$ & 101 & 101 & 101 & 101 & 101 & 101 & 101 & 101 & 101 & 101 \\
\hline \multirow[t]{3}{*}{ Mean RT\&LT mid-thigh USG } & $\mathrm{R}$ & -0.159 & 0.767 & 0.517 & 0.745 & 0.032 & 0.493 & -0.437 & -0.490 & -0.013 & -0.341 \\
\hline & $P$ value & 0.113 & $<0.001$ & $<0.001$ & $<0.001$ & 0.749 & $<0.001$ & $<0.001$ & $<0.001$ & 0.893 & $<0.001$ \\
\hline & $\mathrm{N}$ & 101 & 101 & 101 & 101 & 101 & 101 & 101 & 101 & 101 & 101 \\
\hline \multirow[t]{3}{*}{ USG Quadriceps thickness index } & $\mathrm{R}$ & -0.148 & 0.634 & 0.329 & 0.722 & 0.011 & 0.476 & -0.473 & -0.472 & -0.035 & -0.346 \\
\hline & $P$ value & 0.141 & $<0.001$ & 0.001 & $<0.001$ & 0.912 & $<0.001$ & $<0.001$ & $<0.001$ & 0.729 & $<0.001$ \\
\hline & $\mathrm{N}$ & 101 & 101 & 101 & 101 & 101 & 101 & 101 & 101 & 101 & 101 \\
\hline
\end{tabular}

constitutes an accurate bedside method to diagnose and monitor sarcopenia in cirrhotic patients.

Correlation of ultrasound with HGS is an independent predictor of liver disease severity and poor outcome which are assessed by high Child and MELD score TPI is an efficient index for the assessment of muscle depletion in cirrhotic patients.

Finally, Ultrasound assessment of sarcopenia may allow monitoring the patients' nutritional status over time in a straightforward, bed-side and reproducible manner.

\begin{abstract}
Abbreviations
MELD: Model for end-stage liver disease; FINH: Foundation for National Institutes of Health; HGS: Hand grip strength; CSA: Cross-sectional area; DXA: Dual-energy X-ray absorptiometry; BIA: Bio-electrical impedance analysis; $C T$ : Computed tomography; MRI: Magnetic resonance imaging; ASM: Appendicular skeletal muscle; TMM: Total muscle mass; RF: Rectus femoris; MT: Muscle thickness; FT: Fat thickness; SMI: Skeletal muscle index; FFM: Fat free mass; RT: Right; LT: Left; MUAC: Mid upper arm circumference; QMLT: Quadriceps muscle layer thickness; TPI: Thickness pressure index; AUC: Area under curve; PG-SGA: Patient-generated subjective global assessment; SPSS: Statistical package for the Social Sciences; ANOVA: Analysis of variance.
\end{abstract}

\section{Acknowledgements}

The authors are appreciating the role of the Kasr El-Aini institute and hospital for providing the study with the required type of patient and the help of reaching optimum diagnosis for the proper management service.

\section{Authors' contributions}

NE: Conceived the study, designed it, was the primary radiologist who interpreted the images blindly from the second radiologist, and drafted the manuscript. HK: Participated in the design of the study, revised and adjusted the manuscript. Both authors have read and approved the final version of the manuscript.

\section{Funding}

None to declare.

\section{Availability of data and materials}

The datasets used and analyzed during the current study are available from the corresponding author on reasonable request.

\section{Declarations}

\section{Ethics approval and consent to participate}

The study approved by the Research Ethics Committee of the Faculty of Medicine at Cairo University in Egypt on 201572016; in compliance with the Helsinki Declaration (DoH-oct20081). All patients included in this study gave written informed consent to participate in this research.

\section{Consent for publication}

All patients included in this research gave written informed consent to publish the data contained within this study. If the patient was less than 16 years old, deceased, or unconscious when consent for publication was requested, written informed consent for the publication of this data given by their parent or legal guardian.

\section{Competing interests}

The authors declare that they have no competing interests. 
Received: 4 August 2021 Accepted: 3 October 2021

Published online: 15 December 2021

\section{References}

1. Boutin RD, Yao L, Canter RJ, Lenchik L (2015) Sarcopenia: current concepts and imaging implications. AJR 205:W255-W266

2. Li S, Li H, Ying Hu, Zhu S, Zherong Xu, Zhang Q, Yang Y, Wang Z, Jia Xu (2020) Ultrasound for measuring the cross-sectional area of biceps brachii muscle in sarcopenia. Int J Med Sci 17(18):2947-2953

3. de Souza VA, Oliveira D, Cupolilo EN, Miranda CS, Colugnati FAB, Mansur HN, da Silva Fernandes NM. Rectus femoris muscle mass evaluation by ultrasound: facilitating sarcopenia diagnosis in pre-dialysis chronic kidney disease stages. Clinics, 2018, 73.

4. Pardo E, El Behi H, Boizeau P, Verdonk F, Alberti C, Lescot T (2018) Reliability of ultrasound measurements of quadriceps muscle thickness in critically ill patients. BMC Anesthesiol 18:205

5. McLean RR, Shardell MD, Alley DE et al (2014) Criteria for clinically relevant weakness and low lean mass and their longitudinal association with incident mobility impairment and mortality: the Foundation for the National Institutes of Health (FNIH) Sarcopenia Project. J Gerontol A Biol Sci Med Sci 69:576-583

6. Chen L-K, Liu L-K, Woo J, Assantachai P, Auyeung T-W, Bahyah KS et al (2014) Sarcopenia in Asia: consensus report of the Asian working group for sarcopenia. J Am Med Dir Assoc 15:95-101

7. Cruz-Jentoft AJ, Bahat G, Bauer J, Boirie Y, Bruyère O, Cederholm T et al (2019) Sarcopenia: revised European consensus on definition and diagnosis. Age Ageing 48:16-31

8. Reiss J, Iglseder B, Kreutzer M, Weilbuchner I, Treschnitzer W, Kassmann H et al (2016) Case finding for sarcopenia in geriatric inpatients: performance of bioimpedance analysis in comparison to dual X-ray absorptiometry. BMC Geriatr 16:52

9. Gollie JM, Harris-Love MO, Patel SS, Argani S (2018) Chronic kidney disease: considerations for monitoring skeletal muscle health and prescribing resistance exercise. Clin Kidney J 11:822-831

10. Nijholt W, Scafoglieri A, Jager-Wittenaar H et al (2017) The reliability and validity of ultrasound to quantify muscles in older adults: a systematic review. J Cachexia Sarcopenia Muscle 8:702-712

11. Wilkinson TJ, Gore EF, Vadaszy N, Nixon DGD, Watson EL, Smith AC (2021) Utility of ultrasound as a valid and accurate diagnostic tool for sarcopenia sex-specific cutoff values in chronic kidney disease. J Ultrasound Med 40:457-467

12. Perkisas S, Baudry S, Bauer J et al (2018) Application of ultrasound for muscle assessment in sarcopenia: towards standardized measurements. Eur Geriatr Med 9:739-757

13. Abe T, Loenneke JP, Thiebaud RS (2018) The use of ultrasound for the estimation of muscle mass: one site fits most? J Cachexia Sarcopenia Muscle 9:213-221

14. Rong S, Wang L, Peng Z et al (2020) The mechanisms and treatments for sarcopenia: could exosomes be a perspective research strategy in the future? J Cachexia Sarcopenia Muscle 11:348-365

15. Abe T, Counts BR, Barnett BE, Dankel SJ, Lee K, Loenneke JP (2015) Associations between handgrip strength and ultrasound-measured muscle thickness of the hand and forearm in young men and women. Ultrasound Med Biol 41:2125-2130

16. Takai Y, Ohta M, Akagi R, Kato E, Wakahara T, Kawakami Y et al (2014) Applicability of ultrasound muscle thickness measurements for predicting fat-free mass in elderly population. J Nutr Health Aging 18:579-585

17. Mourtzakis M, Paul WP (2014) Bedside ultrasound measurement of skeletal muscle. Curr Opin Clin Nutr Metab Care 17:389-395

18. Tandon P, Raman M, Mourtzakis M et al (2017) A practical approach to nutritional screening and assessment in cirrhosis AASLD. Hepatology 65:1044-1057

19. Mandill J, Hilwah M, Sinclair I et al (2019) Utilizing bedside ultrasound to assess muscle mass in cirrhotic patients assessed for liver transplantation. J Can Assoc Gastroenterol 2(2):537-538

20. Tandon P, Low G, Mourtzakis M et al (2016) A model to identify sarcopenia in patients with cirrhosis. Clin Gastroenterol Hepatol 14:1473-1480

21. Plauth M, Cabre E, Riggio O et al (2006) ESP enteral nutrition guidelines on enteral nutrition: liver disease. Clin Nutr 25:285-294
22. Álvares-da-Siva MR, Silveira TR (2006) Hand-grip strength or muscle mass in cirrhotic patients: who is the best? Nutrition 22:218-219

23. Studenski SA, Peters KW, Alley DE et al (2014) The FNIH Sarcopenia Project: rationale, study description, conference recommendations, and final estimates. J Gerontol A Biol Sci Med Sci 69:547-558

24. Sheng Z, Yong Z, Qing X et al (2017) Handgrip strength as a predictor of nutritional status in Chinese elderly inpatients at hospital admission. Biomed Environ Sci 30(11):802-810

25. Flood A, Chung A, Parker $\mathrm{H}$ et al (2014) The use of hand grip strength as a predictor of nutrition status in hospital patients. Clin Nutr 33:106-114

26. Gaikwad NR, Gupta SJ, Samarth AR et al (2016) Handgrip dynamometry: a surrogate marker of malnutrition to predict the prognosis in alcoholic liver disease. Ann Gastroenterol 29:509-514

27. Ciocîrlan M, Cazan AR, Barbu M et al (2017) Subjective global assessment and handgrip strength as predictive factors in patients with liver cirrhosis. Hindawi Gastroenterol Res Pract 201:1-5

28. Fernandes SA, de Mattos AA, Tovo CV et al (2016) Nutritional evaluation in cirrhosis: emphasis on the phase angle. World J Hepatol 8(29):1205-1211

29. Gioia S, Lattanzi B, Dambrosio D et al (2018) The assessment of saropenia by quadriceps muscle ultrasound in patients with liver cirrhosis EASL. Clin Nutr 37:S302-\$303

\section{Publisher's Note}

Springer Nature remains neutral with regard to jurisdictional claims in published maps and institutional affiliations.

\section{Submit your manuscript to a SpringerOpen ${ }^{\circ}$ journal and benefit from:}

- Convenient online submission

- Rigorous peer review

- Open access: articles freely available online

- High visibility within the field

- Retaining the copyright to your article

Submit your next manuscript at springeropen.com 